\title{
Analysis of Blast Resistant Structure (TNT Storage Case Study)
}

\author{
Majdi EL. Mukhtar ${ }^{1, *}$ and Abdelmonim A. Haroun ${ }^{2}$ \\ 1 Civil Engineering Department, Al-Zaiem Al-Azhari University, Khartoum, Sudan \\ 2 Civil Engineering Department, University of Karary, Omdurman, Sudan \\ * Corresponding author: Majdi EL. Mukhtar (e-mail: amajdi36@yahoo.com).
}

Article history: Received 27 February 2020, Received in revised form 4 November 2020, Accepted 11 November 2020

\begin{abstract}
The explosions produce extreme and unique loading on structures and can cause widespread damage to the building's structural elements. Design of blast resistant structures provides structural integrity and acceptable levels of safety for buildings. The previous studies show that some structural systems could provide substantial increase in protection against blasts. This paper discussed the behavior of TNT loaded storage (a framed reinforced concrete.) the results of calculated pressure. Using Reference (UFC)-3-340-02 [1] Equation and investigated that the average peak reflected pressure close to 5000 Psi. CSI-ETABS Software 3D model shows that the structural system of case study unsafe under 0.5 tons of TNT internal weight charge.
\end{abstract}

Keywords: Blast, TNT Storage, Reflected Pressure and confined

\section{INTRODUCTION}

This document is a template for Microsoft Explosion in structural engineering usually used to describe any situation where enormous energy is released from a chemical or mechanical nuclear source. However, from the perspective of the effects of the blast load on framed concrete storages that have highly an important factor, it must be designed to resist blast loads which have been recently concern of researchers to find out appropriate structural systems. When explosion occur inside the building such as propellant storages called confined blast, on the other hand the surrounding environment (Human, Buildings and equipment's) is the point of protection from fragments and generated explosion energy. Research by Hu et al. [7] shown that the pressure time-history resulting from the vented confined blast, affected with several factors, including the size of the explosion charge, shape and location of it, as well as the direction and the starting point of detonation in the charge, on the other hand, the confined explosion contains initial and subsequent peak pressure resulting from the shockwave's reflections of the boundary walls of the interior, it is known as gas pressure or quasi static pressure that continues to exist inside the container unless there is an opening to escape. However Baker et al.[8] the study showed one-dimensional or two-dimensional charge in simple form inside a fully closed container that the subsequent peak pressure usually takes half of the initial values as shown in Figure(1). This pressure time-history can be obtained analytically. According to, F.B.A. Beshara [6] the evaluation of explosion-induced ground shocks can be included in a simplified form. An explosion which occurs within a structure normally develops a very complex pressure time-history at any position inside the structure although the complex loading cannot be predicted exactly".

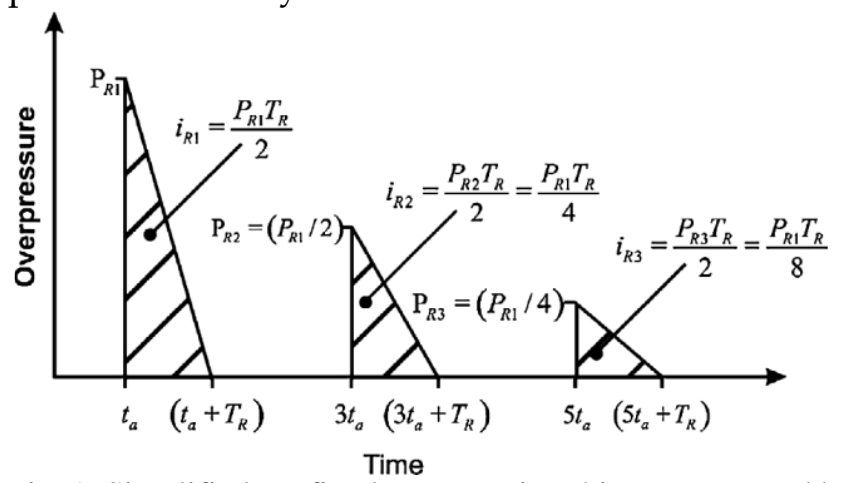

Fig. 1: Simplified confined pressure time-history proposed by Baker et al. [8]. 


\section{BLAST PHENOMENON}

Explosions are classified based on their nature as chemical, physical and nuclear blast. The energy will released as result of the atomic nuclei formed by rearrangement of the protons and neutrons in the interacting nuclei. Physical explosion is the result of mixing highly reactive liquids setting ablaze of explosive materials, exploding of gas cylinders etc. however chemical explosion is a result of quick oxidation of fuels mainly which consists of carbon and hydrogen.

\section{DESCRIPTION OF ANALYSIS MODEL}

The case study consists from single story of reinforced concrete frame element (columns and slab with beams) as shown in fig.(2) and masonry walls designed to prevent the explosion waves, It have $40 \mathrm{~cm}$ thickness located on three directions (back and sides), the overall height of out-site faces of that walls have supported with backfilling, on the other hand, the front wall (10 $\mathrm{cm}$ thickness) oriented to be explosion cloud direction, this structural system can reduce the amount of expected damage around the structure for people and equipment etc. explosive materials exist in quite small quantities, its located as shown in the figure (2), In the following points, time-history peak pressure of confined explosion will be calculated according to reference[1] (UFC)-3-340-02, and investigation of dynamic behavior and response of structures subjected to the blast with CSI-ETABS software.
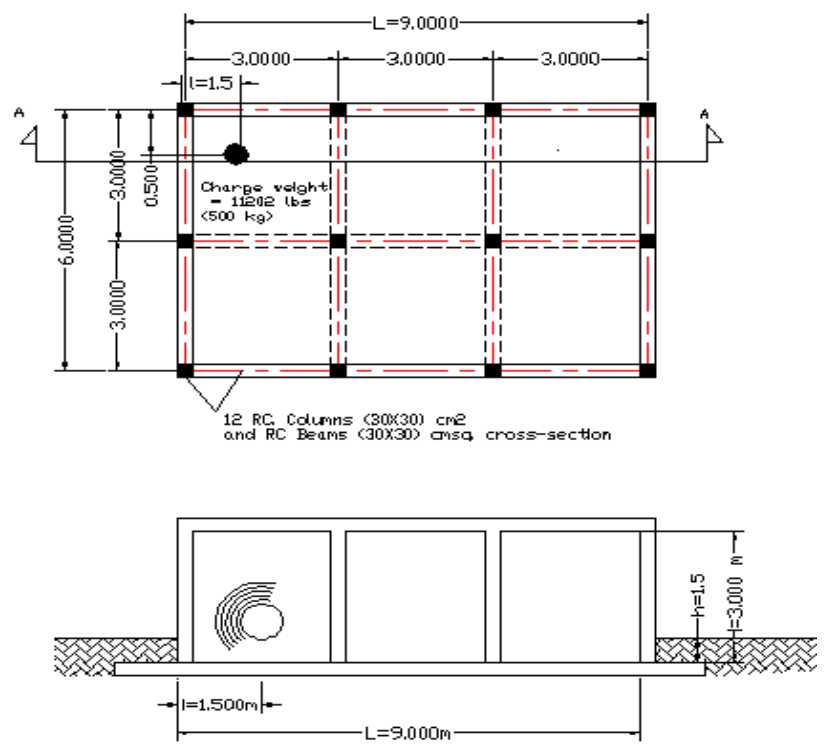

Fig. 2: Analysis Model

\section{STRUCTURAL RESPONSE TO BLAST}

Complexity in analyzing the dynamic response of explosive-loaded structures involves the effect of high strain rates, the non-linear inelastic material behavior, the uncertainties of blast load calculations and the time-dependent deformations. Wherefore, to easily analyze assumptions that related to the response of structures and the loads has been proposed. To establish the principles of this analysis, the structure is idealized as a single degree of freedom (SDOF) system in order to calculate pressure and duration. This leads to blast load idealization and simplifies the classification of the blast loading regimes.

\section{CALCULATIONS AND DISCUSSION}

The average peak reflected pressure and average scaled reflected impulse acting on the Back wall calculated using the equations according to the method given in UF 3-340-02 [1] as shown in the table below:

( $\mathrm{H}=$ overall height, $\mathrm{h}=$ charge height, $\mathrm{L}=$ length)

TABLE (I) AVERAGE PEAK REFLECTED PRESSURE (PSI):

\begin{tabular}{|c|c|c|c|c|c|c|c|c|}
\hline h/H & \multicolumn{4}{|c|}{0.1} & \multicolumn{4}{|c|}{0.25} \\
\hline${ }^{1 / L_{L}}$ & 0.1 & 0.25 & 0.5 & 0.74 & 0.1 & 0.25 & 0.5 & 0.74 \\
\hline 0.625 & 1800 & 2000 & 1900 & 2000 & 1750 & 2800 & 2600 & 2800 \\
\hline 1.25 & 2500 & 2800 & 3000 & 2800 & 3900 & 4000 & 3000 & 4000 \\
\hline 2.5 & 5000 & 5000 & 6500 & 5000 & 4500 & 6000 & 6000 & 6000 \\
\hline 5 & 7500 & 10000 & 7500 & 10000 & 7000 & 10000 & 8500 & 10000 \\
\hline $\mathrm{h} / \mathrm{H}$ & \multicolumn{4}{|c|}{0.5} & \multicolumn{4}{|c|}{0.75} \\
\hline${ }^{1 / L} \quad$ L/H & 0.1 & 0.25 & 0.5 & 0.74 & 0.1 & 0.25 & 0.5 & 0.74 \\
\hline 0.625 & 1800 & 2300 & 2200 & 2300 & 1750 & 2800 & 2600 & 2800 \\
\hline 1.25 & 3000 & 1900 & 4000 & 1900 & 3900 & 4000 & 3000 & 4000 \\
\hline 2.5 & 5000 & 6000 & 6000 & 6000 & 4500 & 6000 & 6000 & 6000 \\
\hline 5 & 6000 & 7000 & 8000 & 7000 & 7000 & 10000 & 8500 & 10000 \\
\hline
\end{tabular}

\begin{tabular}{|c|c|c|c|c|c|c|c|c|}
\hline \multirow{2}{*}{$\begin{array}{l}\mathrm{h} / \mathrm{H} \\
/ \mathrm{L}_{\mathrm{L}}{ }_{\mathrm{L}} \mathrm{H}\end{array}$} & \multicolumn{4}{|c|}{0.1} & \multicolumn{4}{|c|}{0.25} \\
\hline & 0.1 & 0.25 & 0.5 & 0.74 & 0.1 & 0.25 & 0.5 & 0.74 \\
\hline 0.625 & 1800 & 2000 & 1900 & 2000 & 1750 & 2800 & 2600 & 2800 \\
\hline 1.25 & 2500 & 2800 & 3000 & 2800 & 3900 & 4000 & 3000 & 4000 \\
\hline 2.5 & 5000 & 5000 & 6500 & 5000 & 4500 & 6000 & 6000 & 6000 \\
\hline 5 & 7500 & 10000 & 7500 & 10000 & 7000 & 10000 & 8500 & 10000 \\
\hline $\mathrm{h} / \mathrm{H}$ & \multicolumn{4}{|c|}{0.5} & \multicolumn{4}{|c|}{0.75} \\
\hline${ }^{1 / L} \quad L / H$ & 0.1 & 0.25 & 0.5 & 0.74 & 0.1 & 0.25 & 0.5 & 0.74 \\
\hline 0.625 & 1800 & 2300 & 2200 & 2300 & 1750 & 2800 & 2600 & 2800 \\
\hline 1.25 & 3000 & 1900 & 4000 & 1900 & 3900 & 4000 & 3000 & 4000 \\
\hline 2.5 & 5000 & 6000 & 6000 & 6000 & 4500 & 6000 & 6000 & 6000 \\
\hline 5 & 6000 & 7000 & 8000 & 7000 & 7000 & 10000 & 8500 & 10000 \\
\hline
\end{tabular}

TABLE (II) INTEGRATED PRESSURE FROM TABLE (I):

\begin{tabular}{|c|c|c|c|c|c|c|c|}
\hline \multicolumn{2}{|c|}{$\mathbf{0 . 1}$} & \multicolumn{2}{c|}{$\mathbf{0 . 2 5}$} & \multicolumn{2}{c|}{$\mathbf{0 . 5}$} & \multicolumn{2}{c|}{$\mathbf{0 . 7 5}$} \\
\hline $\mathbf{0 . 1}$ & 4000 & 0.1 & 4260 & 0.1 & 4200 & 0.1 & 4260 \\
\hline $\mathbf{0 . 2 5}$ & 4120 & 0.25 & 5200 & 0.25 & 4360 & 0.25 & 5200 \\
\hline $\mathbf{0 . 5}$ & & & & 0.5 & 5200 & 0.5 & 4800 \\
\hline $\mathbf{0 . 7 5}$ & 4120 & 0.75 & 5200 & 0.75 & 4360 & 0.75 & 5200 \\
\hline
\end{tabular}


TABLE (IV) INTEGRATED UNIT IMPLUSE TABLE (2):

\begin{tabular}{|c|c|c|c|c|c|c|c|}
\hline \multicolumn{2}{|c|}{$\mathbf{0 . 1}$} & \multicolumn{2}{c|}{$\mathbf{0 . 2 5}$} & \multicolumn{2}{c|}{$\mathbf{0 . 5}$} & \multicolumn{2}{c|}{$\mathbf{0 . 7 5}$} \\
\hline $\mathbf{0 . 1}$ & 320 & 0.1 & 340 & 0.1 & 334 & 0.1 & 340 \\
\hline $\mathbf{0 . 2 5}$ & 280 & 0.25 & 328 & 0.25 & 328 & 0.25 & 328 \\
\hline $\mathbf{0 . 5}$ & 274 & 0.5 & 326 & 0.5 & 324 & 0.5 & 326 \\
\hline $\mathbf{0 . 7 5}$ & 280 & 0.75 & 328 & 0.75 & 328 & 0.75 & 328 \\
\hline
\end{tabular}
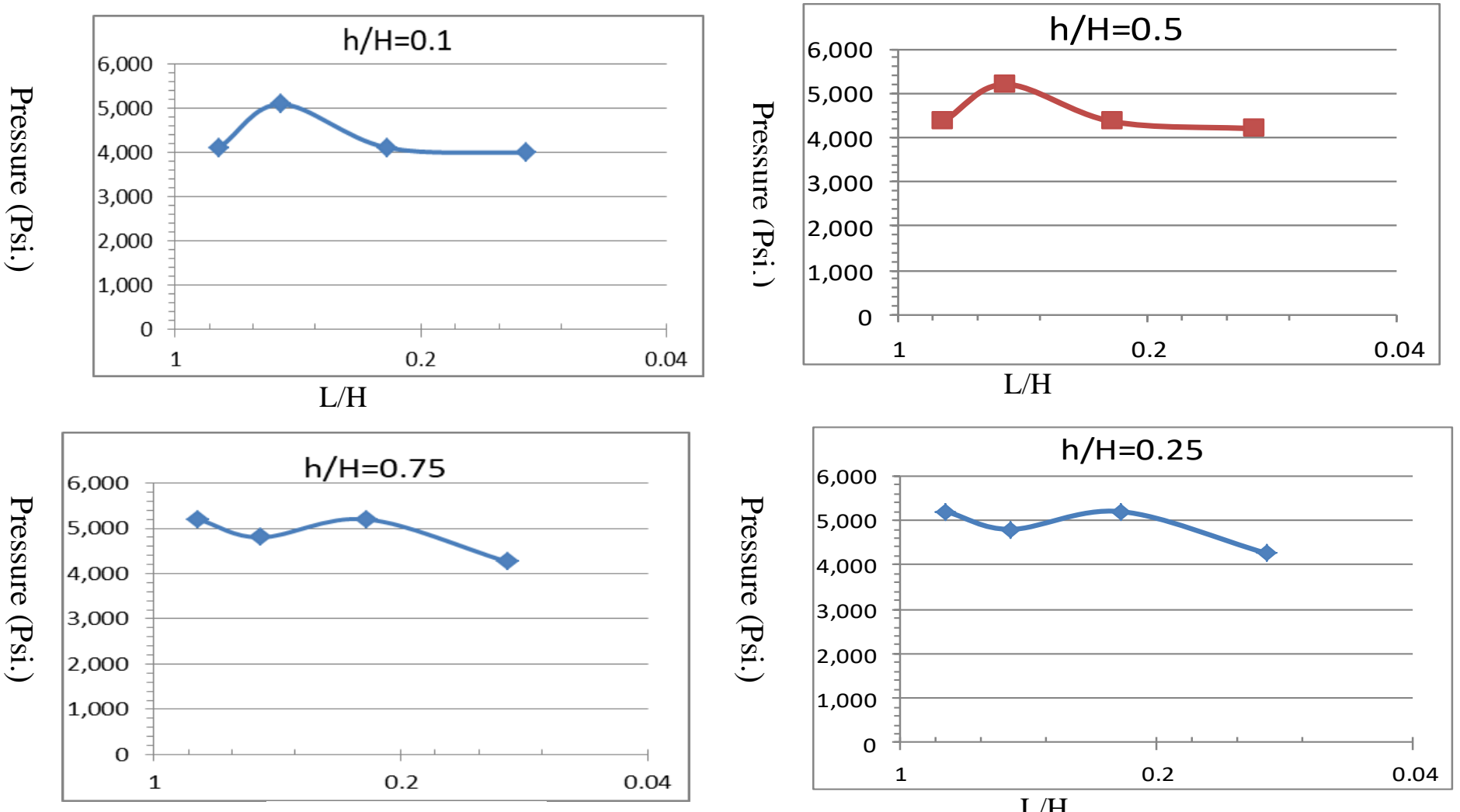

L/H.

Fig. 3: $\log$ Diagram for Pressure\& Duration
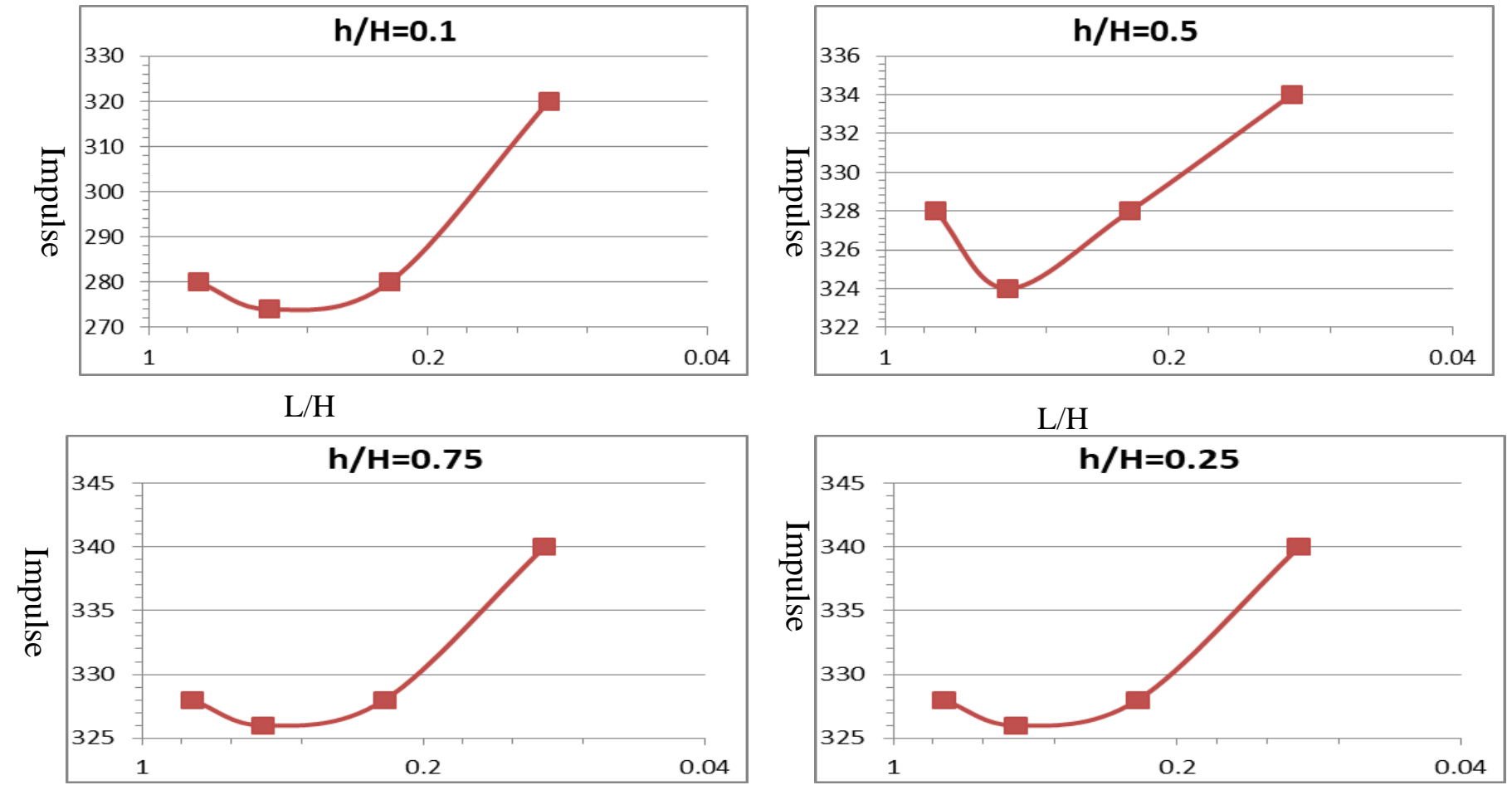

$\mathrm{L} / \mathrm{H}$

Fig. 4: $\log$ Diagram for Impulse \& Duration 


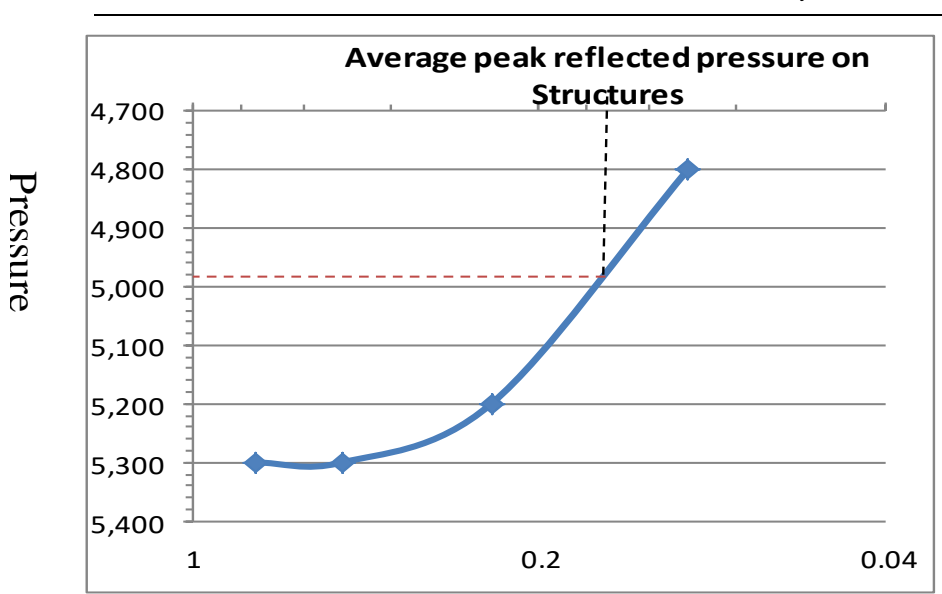

$\mathrm{L} / \mathrm{H}$

\begin{tabular}{c|c}
\hline \hline $\mathrm{h} / \mathrm{H}$ & Average Pressure \\
\hline 0.1 & 4800 \\
\hline 0.167 & 4980 \\
\hline 0.25 & 5200 \\
\hline 0.5 & 5300 \\
\hline 0.75 & 5300 \\
\hline \hline
\end{tabular}

The Peak pressure time-history have been calculated according to UFC-340-20 Ref. [1] equations as shown above Tables (I\&III), this values is very large among existed structural system, it does not need to prove stability of structure under amount of 0.5 TONS of TNT internal loading on the part of structure, however CSI-ETABS model shows that the displacement of joints on the beam columns connection around 9 meters as shown in table (V) this values does not applicable in the structural engineering, indeed whole structures can be fragments which are cause huge damages around it. Hence the structural system currently presented did not approached with amount TNT of inside storage.

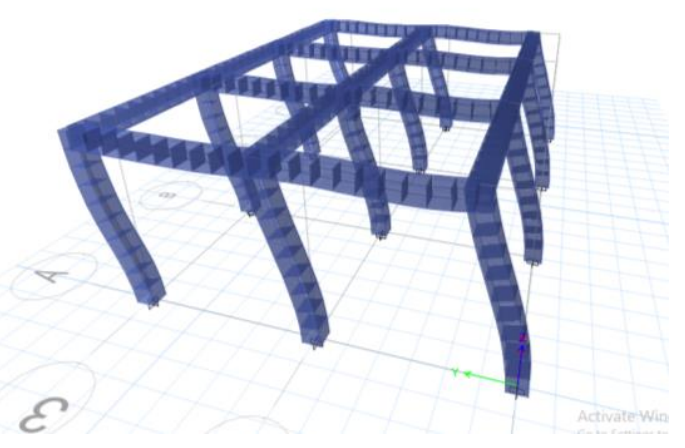

Fig. 7: SCI-ETABS 3D Model dynamic analysis
TABLE (V) JOINTS DISPLACEMENT SCI-ETABS:

\begin{tabular}{|c|c|c|c|c|}
\hline \multirow{2}{*}{ Label } & \multirow{2}{*}{$\begin{array}{c}\text { Naque } \\
\end{array}$} & $\mathbf{U x}$ & $\mathbf{U y}$ & $\mathbf{U z}$ \\
\cline { 3 - 5 } & $\mathbf{m m}$ & $\mathbf{m m}$ & $\mathbf{m m}$ \\
\hline $\mathbf{1}$ & $\mathbf{2}$ & - & 8856.578 & -18.493 \\
\hline $\mathbf{2}$ & $\mathbf{3}$ & - & 8856.578 & -18.493 \\
\hline $\mathbf{3}$ & $\mathbf{5}$ & - & 8856.578 & -18.493 \\
\hline $\mathbf{4}$ & $\mathbf{7}$ & - & 8856.578 & -18.493 \\
\hline $\mathbf{5}$ & $\mathbf{9}$ & - & 8731.397 & -24.851 \\
\hline $\mathbf{6}$ & $\mathbf{1 1}$ & - & 8731.397 & -24.851 \\
\hline $\mathbf{7}$ & $\mathbf{1 3}$ & - & 8731.397 & -24.851 \\
\hline $\mathbf{8}$ & $\mathbf{1 5}$ & - & 8731.397 & -24.851 \\
\hline $\mathbf{9}$ & $\mathbf{1 7}$ & - & 8674.713 & 43.344 \\
\hline $\mathbf{1 0}$ & $\mathbf{1 9}$ & - & 8674.713 & 43.344 \\
\hline $\mathbf{1 1}$ & $\mathbf{2 1}$ & - & 8674.713 & 43.344 \\
\hline $\mathbf{1 2}$ & $\mathbf{2 3}$ & - & 8674.713 & 43.344 \\
\hline
\end{tabular}

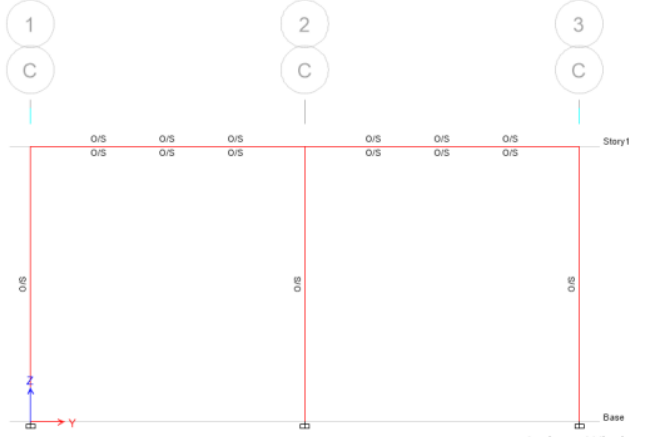

Fig. 5: YY-axis view over stress columns dynamic analysis and design (ETABS)

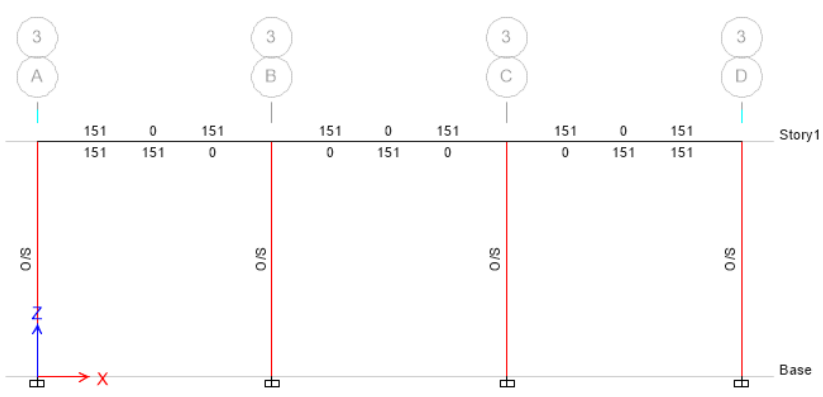

Fig. 6: XX-axis view over stress columns dynamic analysis and design (ETABS)

\section{A. Conclusion}

Analysis of propellants' storages, no matter how small quantities, it high recommended to preventing explosions causes. This paper indicates that the blast resistance systems needs to experimental studies in term of investigate exact response of structure. The internal explosions in storages of propellants are very complicated hence we recommend that structural systems must be underground, in order to achieve design concept, reinforced concrete elements should be high strength and protected from temperature of leakage gas Finally, to develop software model LS-DYANA Program is more likely. 


\section{REFERENCES}

[1] Unified Facilities Criteria (UFC)-3-340-02 (2008), Structures to Resists the Effects of Accidental Explosions, US Army Corps of Engineers, Naval Facilities Engineering Command, Air Force Civil Engineer Support Agency.

[2] Qureshi Rizwan, Shivanand Ghule, Amarnath, Structural Analysis of Blast Resistant Buildings. International Research Journal of Engineering and Technology (IRJET) Aug -2017.

[3] C.F. Zhao, J.Y. Chen, Y. Wang, S.J. Lu. Damage mechanism and response of reinforced concrete containment structure under internal blast loading, Theoretical and Applied Fracture Mechanics 61 (2012) 12-20

[4] T. Ngo, P. Mendis, A. Gupta \& J. Ramsay, Blast Loading and Blast Effects on Structures - An Overview EJSE Special Issue: Loading on Structures (2007).

[5] Zac Liskay, Shane Rugg, Conor Thompson. Blast Resistant Building Design: Building Behavior and Key Elements 2014.

[6] F. B. A. BESHARA MODELLING OF BLAST LOADING ON ABOVEGROUND STRUCTURES-II. INTERNAL BLAST AND GROUND SHOCK, 30 March 1992).

[7] Hu Y, Wu C, Lukaszewicz M, Dragos J, Ren J, Haskett M. Characteristics of confined blast loading in unvented structures. Int J Protect Struct 2011;2(1):21-43

[8] Baker WE, Cox PA, Westine PS, Kulesz JJ, Strehlow RA. Fundamental studies in engineering. Explosion hazards and evaluation, vol. 5. Amsterdam, Oxford, New York: Elsevier; 1983. p. 238-43.

[9] Feldgun VR, Karinski YS, Yankelevsky DZ. Some characteristics of an interior explosion within a room without venting. Struct Eng Mech 2011;38(5):633-49.

[10] Gautham T N1, Dr. M N Hegde 2, Blast Resistant Buildings (2017) International Research Journal of Engineering and Technology (IRJET).

[11] [11] TM5-1300. Structures to resist the effects of accidental explosions. United States Departments of the Army, Navy and Air Force

[12] ] TM5-1300. Structures to resist the effects of accidental explosions. United States Departments of the Army, Navy and Air Force. 